\title{
INFLUÊNCIA DA COMPOSIÇÃO DO MEIO DE CULTIVO E DO TIPO DE EXPLANTE NA MICROPROPAGAÇÃO DO PORTA-ENXERTO DE Prunus sp. 'GXN-9'1
}

\section{INFLUENCE OF CULTURE MEDIUM COMPOSITION AND EXPLANT TYPE ON MICROPROPAGATION OF THE ROOTSTOCK Prunus sp. 'GXN-9'}

\author{
Elizete Beatriz RADMANN² \\ Valmor João BIANCHI ${ }^{3}$ \\ Tatiane Medeiros SOUZA 4 \\ José Carlos FACHINELLO 5 \\ Roberto Pedroso de OLIVEIRA ${ }^{6}$
}

\begin{abstract}
RESUMO
Objetivou-se estudar a composição de diferentes meios de cultura, concentrações de BAP e tipos de explante, na multiplicação in vitro do porta-enxerto ' $G \times N-9$ ', como também a influência desses fatores na ocorrência de vitrificação. Explantes basais cultivados em meio QL e WPM apresentaram as melhores respostas para porcentagem de brotação (80\%). O número de brotações por explante também foi maior com explantes basais, porém apenas aqueles cultivados no meio QL (3 brotações por explante). Os meios QL e WPM permitiram obter o melhor desempenho de crescimento das brotações formadas, para ambos os tipos de explante. Contudo, explantes basais cultivados em meio QL, apresentaram $55 \%$ de vitrificação, ao passo que explantes provenientes do meio WPM, não apresentaram esta anormalidade. Concluiu-se que a redução na concentração de sais com adição de $0,5 \mathrm{mg} \mathrm{dm}^{-3}$ de BAP reduz a vitrificação, promovendo aumento no crescimento das brotações, sem influenciar na formação das mesmas.
\end{abstract}

Palavras-chave: Produção de mudas; pessegueiro, in vitro, citocinina; vitrificação.

\section{ABSTRACT}

The objective of the present work was to study the composition of different culture medium, BAP concentration and explants types on in vitro multiplication of the rootstock ' $G \times N-9$ ', like the influence of this factors in the vitrification. Basal explants cultivated in QL and WPM medium had the better results regarding shooting percentage (80\%). The shoot number per explants was also higher with basal explants when cultivating in QL medium (3 shoot a explant). The medium QL and WPM allowed better growth performance of formed shoots to both explants types. Nevertheless, basal explants cultivated in QL medium had $55 \%$ of vitrification, whereas explants from WPM medium did not show this abnormality. The lower level of salt concentration with $0.5 \mathrm{mg} \mathrm{dm}^{-3}$ BAP reduced vitrification, promoting an increase in shoot growth without affecting formation rates.

Key-words: Nursering; peach; in vitro; citokynin; vitrification.

${ }^{1}$ Parte da Tese de Doutorado do primeiro autor.

${ }^{2}$ Engenheira Agrônoma, Doutora em Agronomia, Bolsista Pós - Doutorado Júnior na Faculdade de Agronomia Eliseu Maciel (FAEM)/Universidade Federal de Pelotas (UFPel). Rua Senador Mendonça, 467, ap. 401, 960.015-200, Pelotas-RS, Brasil. E-mail: eradmann@gmail.com. Autora para correspondência.

${ }^{3}$ Engenheiro Agrônomo, Doutor Prof. Adjunto do Instituto de Biologia da Universidade Federal de Pelotas. Pelotas-RS, Brasil. E-mail: valmorjb@yahoo.com.

${ }^{4}$ Bióloga, mestranda em Fitomelhoramento na Faculdade de Agronomia Eliseu Maciel/Universidade Federal de Pelotas.E-mail: tati_msouza@yahoo.com.br.

${ }^{5}$ Engenheiro Agrônomo, Doutor Prof. Titular do Departamento de Fitotecnia da Faculdade de Agronomia Eliseu Maciel/Universidade Federal de Pelotas. Pelotas-RS, Brasil. E-mail: jfachi@ufpel.tche.br

${ }^{6}$ Engenheiro Agrônomo, Doutor Pesquisador da Embrapa Clima Temperado. Pelotas-RS, Brasil. E-mail: rpedroso@cpact.embrapa.br 


\section{INTRODUÇÃO}

A propagação vegetativa in vitro viabiliza a clonagem de várias espécies, permitindo a formação de indivíduos idênticos a partir de pequenas partes ou células isoladas de uma planta matriz (Souza et al., 2006). Porém, a utilização desta técnica para o gênero Prunus, pode apresentar algumas dificuldades na fase de multiplicação, como o reduzido número de brotações formadas por explante e o baixo crescimento das mesmas.

Além disso, alguns genótipos podem apresentar distúrbios fisiológicos ou morfológicos, conhecidos como vitrificação ou hiperhidricidade. Os explantes vitrificados caracterizam-se por apresentarem folhas translúcidas, túrgidas e com aspecto encharcado, apresentando brotações mal formadas e alongadas, de modo que se cultivados em meio de enraizamento apresentam baixo percentual. Adicionalmente, plantas vitrificadas não sobrevivem ao transplante para o solo porque, dentre outros fatores, possuem menor teor de massa seca que as normais e são menos lignificadas. Sendo assim, este fenômeno pode causar perdas significativas no processo de propagação in vitro, inviabilizando um programa comercial de produção de mudas (Hazarika, 2006).

Dentre os fatores que contribuem para a vitrificação dos explantes cultivados in vitro pode-se destacar as altas concentrações de citocinina no meio de cultura, baixa concentração do agente solidificante, excesso de fatores nutricionais e baixa densidade de fluxo luminoso. Entretanto, vários autores indicam que esta anomalia ocorre com maior freqüência em meio líquidos ou com baixa concentração de ágar, com altas concentrações de íons de amônia e elevadas concentrações de citocinina (Debergh, 1983; Pasqual et al., 1991).

Diante deste contexto, este trabalho objetivou avaliar diferentes meios de cultura, concentração de BAP e tipo de explante para o melhor desenvolvimento das brotações, como também avaliar a ocorrência de vitrificação durante a micropropagação do porta-enxerto 'GxN-9' (Prunus persica x Prunus dulcis).

\section{MATERIALE MÉTODOS}

O presente trabalho foi realizado no Laboratório de Cultura de Tecidos da Embrapa Clima Temperado, sendo o mesmo composto por dois experimentos.

\section{Experimento 1}

Explantes apicais com aproximadamente $0,5 \mathrm{~cm}$ (sem excisão do ápice) do porta-enxerto ' $\mathrm{G} \times \mathrm{N}-9$ ', isolados de plantas pré-estabelecidas in vitro, provenientes do terceiro subcultivo em meio de cultura MS com $0,5 \mathrm{mg} \mathrm{dm}^{-3}$ de BAP foram utilizados como explantes iniciais. Esses foram inoculados em meio $\mathrm{MS}$ e $\mathrm{MS} 3 / 4$ (com redução de $25 \%$ da sua concentração plena), suplementados com $100 \mathrm{mg} \mathrm{dm}^{-3}$ de mio-inositol, $30 \mathrm{~g}$ de sacarose, $7 \mathrm{~g}$ de ágar Vetec ${ }^{\circledR}, 0,01 \mathrm{mg} \mathrm{dm}^{-3} \mathrm{de} A \mathrm{AI}$, combinados com diferentes concentrações de $\operatorname{BAP}(0,0 ; 0,25 ; 0,5$; 0,75 e $\left.1,0 \mathrm{mg} \mathrm{dm}^{-3}\right)$, e pH ajustado para 5,9. Após a inoculação, os frascos contendo os explantes foram transferidos para sala de crescimento com fotoperíodo de $16 \mathrm{~h}$, densidade de fluxo luminoso de $25 u \mathrm{~mol} \mathrm{~m} \mathrm{~m}^{-2} \mathrm{~s}^{-1}$ e temperatura de $25 \pm 2{ }^{\circ} \mathrm{C}$, onde permaneceram durante 30 dias de cultivo.

\section{Experimento 2}

Devido à ocorrência de vitrificação durante o primeiro experimento e no subcultivo seguinte, conduziu-se o segundo ensaio com objetivo de controlar esta anomalia. Para tal, avaliou-se a multiplicação in vitro do porta-enxerto ' $G \times N-9$ ' a partir da composição de diferentes meios (MS, MS $1 / 2 \mathrm{~N}, \mathrm{QL}$ e WPM), suplementados com as vitaminas do meio MS. Sendo combinados a estes, dois tipos de explante (apical) explante sem excisão do ápice, e (basal) explante com excisão do ápice. Cada meio básico foi constituído com $100 \mathrm{mg} \mathrm{dm}^{-3}$ de mioinositol, $30 \mathrm{~g}$ de sacarose, $7 \mathrm{~g}$ de ágar Vetec $\circledast$, 0,01 $\mathrm{mg} \mathrm{dm}{ }^{-3}$ de AIB e $0,5 \mathrm{mg} \mathrm{dm}^{-3}$ de BAP, com $\mathrm{pH}$ ajustado para 5,9 antes da adição do ágar. Após a esterilização dos meios, explantes basais e apicais foram inoculados sob condições assépticas, nos diferentes meios de cultura. Sendo esses provenientes do sexto cultivo em meio MS sem regulador de crescimento. Após a inoculação, o material vegetal foi mantido em sala de crescimento nas mesmas condições do experimento anterior.

\section{Delineamento experimental, variáveis analisadas e análise estatística}

Ambos os experimentos foram conduzidos seguindo-se o delineamento inteiramente casualizado, com quatro repetições, sendo a unidade experimental um frasco contendo cinco explantes. As avaliações foram realizadas ao final de 30 dias da instalação dos experimentos, sendo mensuradas a porcentagem de brotação de explantes, número de brotações por explante, porcentagem de crescimento das brotações, comprimento das brotações formadas, com adição da variável porcentagem de vitrificação no segundo experimento. Os dados experimentais foram avaliados em esquema fatorial, composto pelos fatores, meio de cultura com dois níveis (MS e MS $3 / 4$ ) e concentração de BAP com cinco níveis $(0,0 ; 0,25$; 0,$5 ; 0,75$ e $1,0 \mathrm{mg} \mathrm{dm}^{-3}$ ) para o primeiro experimento e os fatores meio de cultura (MS, MS $1 \frac{1}{2} \mathrm{~N}, \mathrm{QL}$ e WPM) e tipo de explante (apical e basal) no segundo experimento. Os dados obtidos foram submetidos à análise de variância, a $5 \%$ de significância, sendo aplicado teste de Duncan para a comparação de médias para os fatores meio de cultura e tipo de explante, e regressão polinomial para o fator concentração de BAP (Zonta \& Machado, 1984).

\section{RESULTADOS E DISCUSSÃO}

\section{Experimento 1}

A análise de variância dos dados apresentou interação significativa para as variáveis porcentagem de brotações e número de brotações por explante, sendo o meio MS superior ao $\mathrm{MS}^{3} / 4 \mathrm{em}$ todas as concentrações testadas, a exceção da concentração de $0,25 \mathrm{mg} \mathrm{dm}^{-3}$ de BAP para porcentagem de brotação (Figura 1A e 1B). 

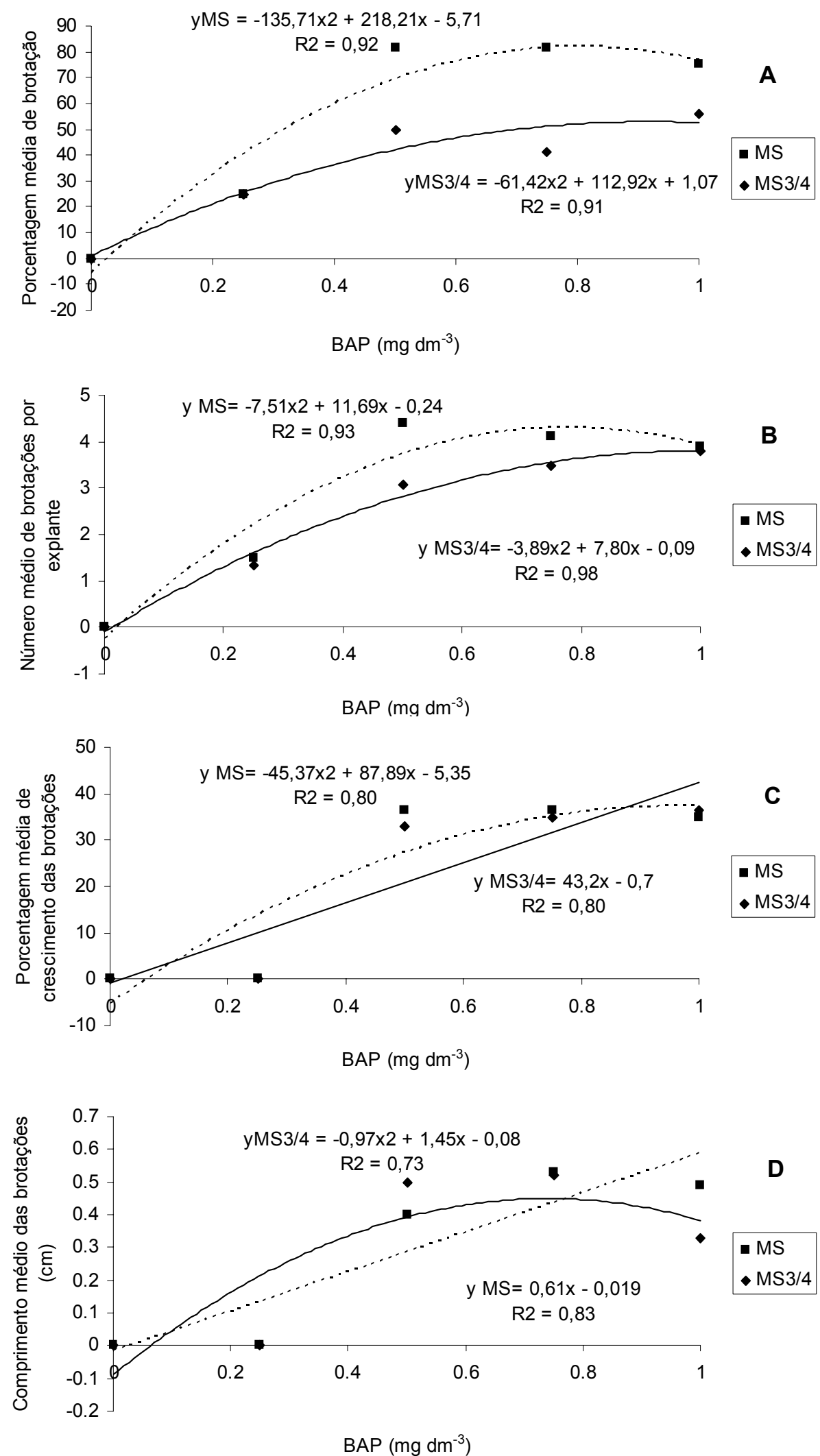

FIGURA 1 - Porcentagem média de brotações por explante (A), número médio de brotações por explante (B), porcentagem média crescimento das brotações (C) e comprimento médio das brotações (D), obtidas com o porta-enxerto 'GxN-9', em meio MS e MS33/4, com diferentes concentrações de BAP. Regressão polinomial ao nível de $5 \%$ de significância. 
A regressão entre as concentrações de BAP demonstrou comportamento quadrático para ambas as variáveis nos meios testados (Figura 1A e 1B). Pela estimativa da equação de regressão, observouse maior resposta na adição de $0,8 \mathrm{mg} \mathrm{dm}^{-3}$ de BAP para porcentagem de explantes brotados em meio MS (82\%), e de $0,91 \mathrm{mg} \mathrm{dm}^{-3}$ de BAP no meio $\mathrm{MS}^{3} / 4$ $(53 \%)$ (Figura $1 \mathrm{~A})$. Com relação ao número de brotações, verificou-se um incremento na multiplicação dos explantes até $0,77 \mathrm{mg} \mathrm{dm}^{-3}$ de BAP (4,3 brotações por explante) quando os explantes foram cultivados em meio MS, enquanto que no meio $\mathrm{MS}^{3} / 4$ a adição de $1,0 \mathrm{mg} \mathrm{dm}^{-3}$ de BAP, resultou em melhor resposta, obtendo 3,81 brotações por explante (Figura 1B).

Embora a resposta quadrática para porcentagem de explantes brotados e número de brotações, em ambos os meios, inferiu pontos de máxima de 0,77 a $1,0 \mathrm{mg} \mathrm{dm}^{-3}$ de BAP, observa-se que $0,5 \mathrm{mg} \mathrm{dm}^{-3}$ de BAP apresenta valores similares aos verificados aos pontos de máxima. Observação similar foi constatada por Sczepanski (2001) e Ponchia \& Gardiman (1993) que indicaram a concentração de $0,5 \mathrm{mg} \mathrm{dm}^{-3}$ de BAP para a multiplicação in vitro do porta-enxerto 'Mirabolano' e de $P$. laurocerasus L., respectivamente.

Couto et al. (2004), estudando as variações na concentração de sais, constataram maior multiplicação de 'Barrier' e 'Cadaman' com 50\% de redução dos sais do meio $\mathrm{MS}$, independente da concentração de BAP. Da mesma forma, o portaenxerto GxN-22 apresentou respostas superiores, quando explantes foram cultivados em meio MS $3 / 4$, comparativamente ao meio na sua concentração plena (Silveira et al., 2001).

Embora no presente trabalho, o meio MS foi o que proporcionou os melhores resultados para a porcentagem de brotações e número de brotações por explante, os explantes apresentaram com maior freqüência sintomas iniciais de vitrificação, em comparação ao MS reduzido. A ocorrência dessa anormalidade, provavelmente, está associada à maior concentração salina no meio MS. Pois, segundo Debergh (1983), um dos fatores que desencadeia a vitrificação é a concentração de sais presente no meio de cultura. No que concerne ao crescimento das brotações formadas, também houve interação significativa entre os fatores meio de cultura e concentração de BAP.

$\mathrm{Na}$ comparação entre a concentração de sais, não se verificou efeito significativo sobre o crescimento das brotações para ambos os meios com adição de $0,25 \mathrm{mg} \mathrm{dm}^{-3}$ de BAP e a testemunha (Figura $1 \mathrm{C}$ e 1D). O meio $\mathrm{MS}$ foi superior ao $\mathrm{MS}^{3} / 4$ em ambas as variáveis, a exceção da concentração de 1,0 ou $0,5 \mathrm{mg} \mathrm{dm}^{-3}$ para as variáveis porcentagem de crescimento das brotações e comprimento das brotações, respectivamente (Figura 1C e 1D).

Quanto as concentrações de BAP, a sua adição ao meio de cultura influenciou o crescimento das brotações, sendo que sua porcentagem no meio MS respondeu positivamente com incremento da citocinina até $0,96 \mathrm{mg} \mathrm{dm}^{-3}$, com uma média de $37,2 \%$ (Figura $1 \mathrm{C}$ ). Porém, nos tratamentos com
$\mathrm{MS} 3 / 4$ observou-se comportamento linear (Figura 1C). Para a variável comprimento das brotações, o aumento da concentração de BAP no meio $\mathrm{MS}^{3} / 4$ foi positivo até $0,74 \mathrm{mg} \mathrm{dm}^{-3}$ e a partir desta concentração ocorreu inibição de crescimento das brotações (Figura 1D). Entretanto, verificou-se uma tendência linear quando explantes foram cultivados em meio MS (Figura 1D).

Comparando-se a tendência quadrática e os valores numéricos para o meio MS na variável porcentagem de crescimento das brotações, verificou-se que a concentração de $0,5 \mathrm{mg} \mathrm{dm}^{-3}$ de BAP apresentou valor similar ao ponto de máxima $\left(0,96 \mathrm{mg} \mathrm{dm}^{-3}\right)$. Para o comprimento das brotações, a concentração de $0,5 \mathrm{mg} \mathrm{dm}^{-3}$ de BAP também apresentou valores similares ao ponto de máxima $\left(0,74 \mathrm{mg} \mathrm{dm}^{-3}\right)$. Este resultado esta condizente com Channuntapipat et al. (2003) que verificaram acréscimo no crescimento das brotações até a concentração $0,67 \mathrm{mg} \mathrm{dm}^{-3}$ de BAP, e a partir desta ocorreu inibição no crescimento das brotações de amendoeira (Prunus dulcis) cv. Nonpareil. Segundo Grattapaglia \& Machado (1998), concentrações crescentes de citocinina podem reduzir ou inibir o crescimento das brotações. Isso ocorre, pois, esse regulador de crescimento é eficaz na indução de brotações, porém quando em excesso é tóxico, caracterizando-se principalmente pela falta de alongamento das culturas, engrossamento do caule e vitrificação generalizada.

Apesar da obtenção de bons resultados na formação de brotações para o porta-enxerto ' $\mathrm{GxN}$ 9', o crescimento observado destas é pouco expressivo e não adequado para a fase de enraizamento. Todavia, este fato parece ser uma característica comum para muitas espécies e cultivares do gênero Prunus, obtendo, na maioria dos trabalhos, altura inferior a 1,0 cm (Matias, 1995; Sczepanski, 2001; Channuntapipat, et al., 2003; Couto et al., 2004; Silva, 2004; Rocha, 2006). No entanto, Leontiev-Orlov et al. (2000) conseguiram brotações de até $6,8 \mathrm{~cm}$ para cultivares de ameixeira. Este resultado reforça os relatos encontrados na literatura, ou seja, que cultivares de pessegueiro apresentam maior dificuldade para o cultivo in vitro, quando comparadas com as ameixeiras.

Além da influência do genótipo, o tipo de explante inicial utilizado para a formação das brotações, também, pode estar relacionado com o baixo crescimento obtido no atual trabalho. Visto que, nos explantes apicais pode estar ocorrendo uma dominância da gema apical em relação as axilares, o que contribuiu para um baixo porcentual de crescimento. Silveira et al. (2001), estudando o comportamento de vários porta-enxertos de Prunus, a partir de segmentos nodais, obtiveram brotações de 'GxN-22' com 1,5 cm de altura. Por outro lado, Matias (1995), usando explantes sem a excisão do ápice, obteve brotações com 0,52 e 0,37 cm de altura para as cultivares Flordaprince e Diamante, respectivamente, resultado este, similar ao encontrado no presente trabalho. 
Além do baixo crescimento das brotações obtidas no presente trabalho e devido à ocorrência de alguns explantes vitrificados, principalmente no meio MS, torna-se necessário estudar o efeito de outros fatores envolvidos na multiplicação do portaenxerto ' $G \times N-9$ ', pois, anomalias, como vitrificação e baixo tamanho de brotações são características indesejáveis e determinantes na qualidade do material destinado a fase de enraizamento. Portanto, conduziu-se o segundo experimento com o propósito de avaliar o efeito de meios com diferentes concentrações salinas combinadas com dois tipos de explante.

\section{Experimento 2}

Verificou-se interação significativa dos fatores para as variáveis porcentagem de brotação, de vitrificação e de crescimento das brotações formadas, bem como para o comprimento médio destas. No entanto, o número de brotações por explante foi influenciado dentro de cada fator isolado.
Com relação ao número de brotações, os explantes basais originaram maior resposta quando comparado com o explante apical, com 3,03 e 2,67 brotações, respectivamente (Tabela 1 ). Resultados similares foram encontrados em macieira cv. Marubakaido, onde explantes basais formaram maior número de brotações em comparação aos explantes apicais (Pereira \& Fortes, 2001). Diferentemente, para macieira cv. MM-111 e pereira cv. Carrik, não se observou efeito significativo entre explantes com e sem excisão do ápice (Leite, 1995; Pereira \& Fortes, 2001). Essas observações estão de acordo com Santos-Serejo et al. (2006) o qual descreve que, além da adição de citocinina no meio de cultura básico para estimular maior proliferação, tratamentos aplicados ao explante, como a excisão do ápice, podem contribuir significativamente para a multiplicação. Porém, de acordo com os resultados obtidos neste trabalho e em comparação com os demais estudos citados o efeito do tipo de explante é dependente do genótipo.

TABELA 1 - Número médio de brotações por explante obtidos com o porta-enxerto 'GxN-9' a partir de diferentes tipos de explante.

\begin{tabular}{lc}
\hline Tipo de explante & Número de brotações por explante \\
\hline Basal & $3,03 \mathrm{~A}^{1}$ \\
Apical & $2,67 \mathrm{~B}$ \\
\hline C.V.(\%) & 20,21 \\
\hline Médias seguidas de mesma letra maiúscula, na coluna, não diferem significativamente entre si, ao nível de $5 \%$ de \\
probabilidade, pelo teste de Duncan.
\end{tabular}

Entre as concentrações de sais, verificouse maior índice para esta variável nos meios QL e MS, com 3,37 brotações por explante, sendo estes superiores em $18,1 \%$ em relação ao WPM e $42,43 \%$ ao $\mathrm{MS}^{1} / 2 \mathrm{~N}$ (Tabela 2). De forma semelhante, Rocha (2006) não constatou efeito significativo entre os meios QL e MS para os porta-enxertos de Prunus Mr. S. $2 / 5$ e Sírio. Por outro lado, em pesquisas conduzidas com videira na comparação de diferentes meios básicos, os autores verificaram que o meio QL foi superior para número de brotações e altura destas em relação ao MS e WPM (Machado et al., 2007). Em contrapartida, o meio de cultura MS promoveu maior indução de brotações $(2,5$ brotações por explante) quando comparado com os macro e micronutrientes do meio QL, que induziu 1,4 brotações por explante, para o porta-enxerto de macieira 'seleção 69' (Santa-Catarina et al., 2001).

TABELA 2 - Número médio de brotações por explante obtidos com o porta-enxerto 'GxN-9' a partir de diferentes meios de cultura.

\begin{tabular}{|c|c|}
\hline Meio de cultura & Número de brotações por explante \\
\hline QL & $3,37 \mathrm{~A}^{1}$ \\
\hline MS & $3,37 \mathrm{~A}$ \\
\hline WPM & $2,76 \quad B$ \\
\hline $\mathrm{MS} 1 / 2 \mathrm{~N}$ & $1,94 \quad \mathrm{C}$ \\
\hline C.V.(\%) & 20,21 \\
\hline
\end{tabular}

probabilidade, pelo teste de Duncan.

Com relação à porcentagem de brotação, os resultados foram semelhantes aos obtidos para o número de brotações por explante. Na comparação entre os tipos de explante, observou-se maior resposta para os explantes basais em todos os meios, com exceção do meio QL, onde explantes apicais foram superiores aos basais, mas apenas em 10\% (Tabela 3). Quando comparamos os diferentes meios, a adição de macro e micronutrientes do meio QL resultaram em maior porcentagem de brotação em relação aos demais, sendo, porém não diferente do meio WPM, quando utilizado o explante de origem basal (Tabela 3 ). 
RADMANN, E.B. et al. Influência da composição do meio de cultivo...

TABELA 3 - Porcentagem de brotação, de vitrificação, de crescimento e comprimento das brotações obtidos com o porta-enxerto 'GxN-9' em diferentes meios de cultura, com explantes apical e basal.

\begin{tabular}{|c|c|c|c|c|}
\hline \multirow{2}{*}{ Tipo de explante } & \multicolumn{4}{|c|}{ Brotação (\%) } \\
\hline & MS & $M S^{1} / 2$ & Q & WPM \\
\hline Apical & $40 \mathrm{~B} \mathrm{C}^{\top}$ & $40 \mathrm{BC}$ & $90 \mathrm{Aa}$ & $50 \mathrm{~B} \mathrm{~b}$ \\
\hline Basal & $70 \mathrm{~A} \mathrm{~b}$ & $65 \mathrm{Ac}$ & $80 \mathrm{~B}$ a & $80 \mathrm{~A} \mathrm{a}$ \\
\hline \multirow[t]{2}{*}{ C.V.(\%) } & \multicolumn{4}{|c|}{8,87} \\
\hline & \multicolumn{4}{|c|}{ Vitrificação (\%) } \\
\hline Apical & $65 \mathrm{~B} \mathrm{a}$ & $65 \mathrm{Aa}$ & $0 \mathrm{~B} \mathrm{~b}$ & $0 \mathrm{Ab}$ \\
\hline Basal & $70 \mathrm{~A} \mathrm{a}$ & $40 \mathrm{~B} \mathrm{C}$ & $55 \mathrm{~A} \mathrm{~b}$ & $0 \mathrm{Ad}$ \\
\hline \multirow[t]{2}{*}{ C.V.(\%) } & \multicolumn{4}{|c|}{20,00} \\
\hline & \multicolumn{4}{|c|}{ Crescimento das brotações (\%) } \\
\hline Apical & $45 \mathrm{~A} \mathrm{C}$ & $36 \mathrm{Ad}$ & $78 \mathrm{~B} \mathrm{~b}$ & $89 \mathrm{~A} \mathrm{a}$ \\
\hline Basal & $0 \mathrm{~B} \mathrm{C}$ & $0 \mathrm{~B} \mathrm{C}$ & $100 \mathrm{~A} \mathrm{a}$ & $48 \mathrm{~B} \mathrm{~b}$ \\
\hline \multirow[t]{2}{*}{ C.V.(\%) } & \multicolumn{4}{|c|}{33,31} \\
\hline & \multicolumn{4}{|c|}{ Comprimento das brotações $(\mathrm{cm})$} \\
\hline Apical & $0,25 \mathrm{~A} \mathrm{C}$ & $0,25 \mathrm{Ac}$ & $0,76 \mathrm{~B} \mathrm{~b}$ & $0,80 \mathrm{~A} \mathrm{a}$ \\
\hline Basal & $0,00 \mathrm{~B} \mathrm{c}$ & $0,00 \mathrm{~B} \mathrm{c}$ & $1,10 \mathrm{~A} a$ & $0,70 \mathrm{~B} \mathrm{~b}$ \\
\hline C.V.(\%) & \multicolumn{4}{|c|}{26,34} \\
\hline
\end{tabular}

${ }^{1}$ Médias seguidas de mesma letra maiúscula na coluna, não diferem significativamente entre si, para o fator explante, dentro do fator meio e minúscula na linha, não diferem entre si, para o fator meio dentro do fator tipo de explante, ao nível de $5 \%$ de probabilidade, pelo teste de Duncan.

Quanto ao crescimento das brotações formadas, constatou-se que composições mais diluídas em macronutrientes (QL e WPM) tiveram melhor desempenho, tanto para porcentagem de crescimento, como para comprimento médio das brotações, para ambos os tipos de explante (Tabela 3 ). Entretanto, as respostas apresentaram-se melhor quando os explantes foram provenientes do meio QL, obtendo um crescimento de $100 \%$ das brotações, com uma média de $1,10 \mathrm{~cm}$, utilizando explantes basais (Tabela 3). Diferentemente, Chevreau \& Leblay (1993) obtiveram maior altura das brotações de pereira, cv. Crassane, com os explantes apicais.

Em uma análise conjunta dos dados obtidos para as variáveis relatadas acima, verificouse que o meio QL apresentou os melhores resultados com explantes basais. No entanto, confrontando-se este tratamento com a porcentagem de vitrificação, constatou-se que 55\% dos explantes inoculados estavam vitrificados, ao passo que na utilização de explantes apicais não se observou esta anormalidade (Tabela 3 ). Este fato, possivelmente, esteja atribuído à superação da dominância apical realizada nos explantes basais. Assim, estes necessitariam de uma menor concentração de BAP para a indução de brotações, sendo a concentração utilizada tóxica, levando consequentemente a vitrificação das mesmas. Santos-Serejo et al. (2006) relatam que a ocorrência de vitrificação está associada a diversos fatores, entre eles a presença de BAP no meio de cultura.

De forma análoga, no meio $M S$, a vitrificação foi mais acentuada nos explantes basais (Tabela 3). Diferentemente, a porcentagem de explantes vitrificados no meio MS com a redução das fontes de nitrogênio $\left(\mathrm{MS}^{1} / 2 \mathrm{~N}\right)$, foi superior com explantes apicais, em 15\%, em relação aos basais (Tabela 3 ).
Isto, provavelmente, ocorreu devido a um efeito residual no explante do subcultivo anterior. Contudo, de forma geral, as maiores anormalidades ocorreram no meio MS com sua concentração plena, seguido do $M S \frac{1}{2} N$ e $Q L$. Este resultado, provavelmente, está associado a maior concentração de nitrogênio na forma amoniacal no meio MS, seguida do MS $1 / 2 \mathrm{~N}$ e do QL. Grattapaglia \& Machado (1998) relataram que a redução da concentração da fonte de nitrogênio, principalmente na forma amoniacal, tem sido utilizada para combater a vitrificação. Entretanto, mesmo com a redução de $50 \%$ das fontes de nitrogênio no meio MS $1 / 2 \mathrm{~N}$, essa anormalidade continuou bastante expressiva, representando $65 \%$ e $40 \%$ de vitrificação. De forma semelhante, o meio $\mathrm{QL}$, que contém metade da concentração de nitrogênio $\left(\mathrm{NH}_{4} \mathrm{NO}_{3}\right)$ em comparação ao $\mathrm{MS} 1 / 2 \mathrm{~N}$, ainda se constatou alta porcentagem de vitrificação, porém, apenas nos explantes basais, onde metade destes vitrificaram. Portanto, apenas no WPM, não foi observada esta anomalia (Tabela 3 ). Este resultado evidencia mais uma vez que a ocorrência de vitrificação está relacionada com a concentração de nitrogênio, o qual está presente na composição no meio WPM, em uma concentração total mais baixa que nos demais meios estudados.

\section{CONCLUSÃO}

Nas condições experimentais adotadas, pode-se concluir que explantes basais cultivados em meio de cultura com maior redução de sais e concentração de BAP até $0,5 \mathrm{mg} \mathrm{dm}^{-3}$, favorecem a multiplicação in vitro do porta-enxerto 'GxN-9', porém, explantes basais também contribuem para a ocorrência de vitrificação. 


\section{AGRADECIMENTO E CONFLITOS DE INTERESSE}

Ao Conselho Nacional de Desenvolvimento Científico e Tecnológico (CNPq) pelo apoio através da concessão da bolsa de Doutorado.

O presente trabalho não apresenta conflitos de interesses que sejam do conhecimento dos autores.

\section{REFERÊNCIAS}

1. CHANNUNTAPIPAT, C.; SEDGLEY, M.; COLLINS, G. Micropropagation of almond cultivars Nonpareil and Ne Plus Ultra and the hybrid rootstock Titan x Nemaguard. Scientia Horticulturae, v. 98, n. 4, p. 473-484, 2003.

2. CHEVREAU, E.; LEBLAY, C. The effect of mother plant pretreatment and explant choice on regeneration from in vitro pear leaves. Acta Horticulturae, v. 336, p. 263-268, 1993.

3. COUTO, M.; OLIVEIRA, R. P.; FORTES, G. R. L. de. Multiplicação in vitro dos porta-enxertos de Prunus sp. cv. Barrier e Cadman. Revista Brasileira de Fruticultura, v. 26, n. 1, p. 5-7, 2004.

4. DEBERGH, P. C. Effects of agar brand and concentration of the tissue culture medium. Physiologia Plantarum, v. 59, n. 2, p. $270-276,1983$

5. GRATTAPAGLIA, D.; MACHADO, M. A. Micropropagação. In: TORRES, A. C.; CALDAS, L. S.; BUSO, J. A. (Ed.). Cultura de tecidos e transformação genética de plantas. Brasília: Embrapa-SPI/Embrapa-CNPH, 1998. p. 183-260.

6. HAZARIKA, B. N. Morpho-physiological disorders in in vitro culture of plants. Scientia Horticulturae, v. 108, n. 2, p. 105120, 2006.

7. LEITE, G. B. Efeito de reguladores de crescimento, substratos, sacarose e intensidade luminosa na micropropagação de pereira (Pyrus communis, L.) cv. Bartlett e clone OHxF97. 1995. 50 f. Dissertação (Mestrado em Melhoramento genético vegetal) - Curso de Pós-Graduação em Agronomia, Universidade Federal de Pelotas, Pelotas, 1995.

8. LEONTIEV-ORLOV, O. et al. 6-Benzilaminopurina (BAP) na multiplicação in vitro de prunáceas (Prunus sp.). Revista Brasileira de Agrociência, v. 6, n. 1, p. 42-46, 2000.

9. MACHADO, M. P. et al. Meios de cultura na micropropagação do porta-enxerto de videira 'VR043-43' (Vitis vinifera $\mathrm{x}$ Vitis rotundifolia). Ciência Rural, v. 37, n. 1, p. 277-280, 2007.

10. MATIAS, A. C. Estabelecimento e multiplicação in vitro de pessegueiro (Prunus persica L. Batsch), cultivares flordaprince e diamante. 1995. 84 f. Dissertação (Mestrado em Fruticultura de Clima Temperado) - Curso de PósGraduação em Agronomia, Universidade Federal de Pelotas, Pelotas, 1995.

11. PASQUAL, M. et al. Influência de 6-benzylaminopurina, sacarose e ágar sobre a vitrificação de brotos de pereira in vitro. Pesquisa Agropecuária Brasileira, v. 26, n. 11/12, p. 1919-1924, 1991.

12. PEREIRA, J. E. S; FORTES, G. R. de L. Multiplicação e aclimatização da macieira influenciada pelo tipo de explante e pelo tempo de permanência em meio de cultura de enraizamento. Revista Brasileira de Fruticultura, v. 23, n. 2, p. 417-420, 2001.

13. PONCHIA, G.; GARDIMAN, M. The micropropagation and post-acclimation growth of Prunus laurocerasus L. cv. Otto Luyken: additional findings. HortScience, v. 28, n. 7, p. 11-14, 1993.

14. ROCHA, P. S. G. Propagação in vitro de porta-enxertos do gênero Prunus spp. 2006. 101 f. Tese (Doutorado em Fruticultura de Clima Temperado) - Curso de Pós-Graduação em Agronomia, Universidade Federal de Pelotas, Pelotas, 2006.

15. SANTA-CATARINA, C. et al. Micropropagação do porta-enxerto de macieira 'seleção 69' tolerante à podridão do colo (Phytophthora cactarum). Ciência Rural, v. 31, n. 5, p. 757-762, 2001.

16. SANTOS-SEREJO, J. A. et al. Meios nutritivos para micropropagação de plantas. In: SOUZA, A. S.; JUNGHANS, T. G. (Ed.). Introdução à micropropagação de plantas. Cruz das Almas: Embrapa Mandioca e Fruticultura Tropical, 2006. p. 80-98.

17. SCZEPANSKI, P. H. G. Propagação in vitro do porta enxerto de ameixeira mirabolano (Prunus cerasifera Ehrh.). 2001. 51 f. Dissertação (Mestrado em Fruticultura de Clima Temperado) - Curso de Pós-Graduação em Agronomia, Universidade Federal de Pelotas, Pelotas, 2001.

18. SILVA, E. S. B. da. Propagação in vitro de Prunus spp. 2004. 115 f. Tese (Doutorado em Fruticultura de Clima Temperado) - Curso de Pós-Graduação em Agronomia, Universidade Federal de Pelotas, Pelotas, 2004.

19. SILVEIRA, C. A. P. et al. Multiplicação in vitro de porta-enxertos do gênero Prunus sob diferentes concentrações de BAP em dois meios de cultura. Revista Brasileira de Fruticultura, v. 23, n. 3, p. 488-492, 2001.

20. SOUZA, F. V. D. et al. (Ed.). Introdução à micropropagação de plantas. Cruz das Almas: Embrapa Mandioca e Fruticultura Tropical, 2006, p. 38-52.

21. ZONTA, E. P.; MACHADO, A. A. SANEST - Sistema de Análise para microcomputadores. Pelotas: UFPel, 1984. 75 p. 
